\title{
Sistem Pengamanan Anonym dengan Menggunakan Algoritma Kriptografi ElGamal
}

\author{
Ni Komang Ayu Sri Anggreni ${ }^{1}$, Linawati $^{2}$, I Nyoman Putra Sastra ${ }^{3}$ \\ [Submission: 20-04-2019, Accepted: 30-06-2019]
}

\begin{abstract}
Reporting on act of domestic violence to Integrated Services Center for Woman and Children (Pusat Pelayanan Terpadu Pemberdayaan Perempuan dan Anak (P2TP2A)) Denpasar City is kind of sensitive and vulnerable data to tapping. As a result, security guarantee for the reporter is needed to protect their identity. Security guarantee with anonym reporting system, which uses EIGamal cryptographic algorithm for encryption process and description process. EIGamal cryptographic algorithm is one of asymmetric cryptography which consist of 3 processes, that are process of generate key, encryption process and description process On this security system identity of the reporter will be protected through process of authentication, authorization, and encryption. In this study the researcher uses Android platform and EIGamal cryptographic algorithm for encryption and description, Firebase Auth for authentication, Firebase Rules for authorization and Avalanche Effect for knowing the quality of cryptographic algorithm. The result of the trials which used 10 different ciphet texts of avalanche effect is $58,2 \%$. That result can be categorized as good because a good result of avalanche effect.
\end{abstract}

Intisari- Pelaporan tindak kekerasan rumah tangga pada Pusat Pelayanan Terpadu Pemberdayaan Perempuan dan Anak (P2TP2A) Kota Denpasar merupakan data yg sensitive dan rawan terhadap penyadapan. Maka dari itu diperlukan jaminan keamanan kepada pelapor pengaduan agar identitasnya dapat dilindungi. Jaminan keamanan yang dimaksud adalah sistem pelaporan tindak kekerasan dengan pengamanan yang anonym, menggunakan algoritma kriptografi ElGamal untuk proses enkripsi dan proses dekripsi. Algoritma kriptografi ElGamal merupakan salah satu jenis kriptografi asimetris dimana terdiri dari tiga proses yaitu proses pembentukan kunci, proses enkripsi dan proses dekripsi. Pada sistem pengamanan ini identitas pelapor dijaga kerahasiaannya dan terbukti kebenarannya melalui proses autentikasi, otorisasi, dan enkripsi. Dalam studi ini menggunakan platform Android dan algoritma kriptografi ElGamal untuk enkripsi dan dekripsi, Firebase Auth untuk autentikasi, Firebase Rules untuk otorisasi serta Avalanvhe Effect untuk mengetahui baik tidaknya algoritma kriptografi. Dari hasil uji coba dengan menggunakan 10 cipher text yang berbeda diketahui bahwa hasil perhitungan avalanche effect yang dihasilkan rata-rata $58,2 \%$. Hasil tersebut dikatakan baik mengingat avalanche effect dikategorikan baik apabila berkisar antara 40-60\%.

${ }^{1}$ Mahasiswa, Program Studi Teknik Elektro Fakultas Teknik Universitas Udayana, Jalan Kampus Bukit Jimbaran 80361 INDONESIA telp: 0361-703315; fax: 0361-703315

${ }^{2,3}$ Staff Pengajar, Program Studi Teknik Elektro Fakultas Teknik Universitas Udayana, Jalan Kampus Bukit Jimbaran 80361 INDONESIA telp: 0361-703315; fax: 0361-703315
Kata Kunci-Kriptografi, Enkripsi, Android, ElGamal

\section{Pendahuluan}

Saat ini perkembangan teknologi informasi salah satunya internet sangatlah berpengaruh hampir pada seluruh aspek kehidupan manusia termasuk dalam berkomunikasi. Namun, banyak terjadi penyadapan informasi yang dilakukan oleh pihak yang tidak bertanggung jawab sehingga menyebabkan internet tidaklah terlalu aman. Karena banyaknya yang menggunakan internet, maka perlu dipikirkan untuk memberikan jaminan keamanan pada data yang sensitive, terutama data yang hanya bisa diketahui oleh pihak tertentu saja.

Salah satu contoh sistem yang mempunyai data sensitive adalah pada pelaporan tindak kekerasan pada Pusat Pelayanan Terpadu Pemberdayaan Perempuan dan Anak (P2TP2A) Kota Denpasar. Pelapor pengaduan pada sistem ini diberikan jaminan keamanan agar identitasnya dapat dilindungi. Jaminan keamanan yang dimaksud adalah sistem pelaporan tindak kekerasan dengan pengamanan yang anonym, menggunakan algoritma kriptografi untuk proses enkripsi dan proses dekripsi [1]. Dalam sistem pelaporan ini akan dilakukan sedikit pengembangan dengan menggunakan metode algoritma kriptografi ElGamal.

Ciphertext yang dihasilkan oleh algoritma ElGamal akan selalu berbeda meskipun menggunakan kunci dan pesan yang sama sehingga hal tersebut merupakan keunggulan daripada algoritma ElGamal sehingga tingkat keamanan yang dihasilkan lebih tinggi. Hal tersebut membuat jumlah karakter chipertext yang dihasilkan lebih banyak sehingga membutuhkan waktu yang lama apabila sistem akan di retas serta kecepatan waktu proses enkripsi dan dekripsi akan menjadi lebih lambat [2].

Dibandingkan dengan algoritma asimetris lainnya, algoritma kriptografi ElGamal lebih aman karena menghasilkan ciphertext lebih kompleks sehingga membutuhkan waktu yang lambat ketika mengenkripsi dan mendekripsi [3]. Maka dari itu, dalam sistem pengamanan ini identitas pelapor akan dijaga kerahasiaannya dan terbukti kebenarannya melalui proses autentikasi, otorisasi, dan enkripsi. Pengamanan anonym untuk identitas pelapor pada aplikasi Android ini akan menggunakan algoritma kriptografi ElGamal untuk enkripsi dan dekripsi, Firebase Auth untuk autentikasi, serta Firebase Rules untuk otorisasi.

\section{KRIPTOGRAFI ELGAMAL}

\section{A. Autentikasi}

Proses validasi user pada saat memasuki sistem dinamakan dengan autentikasi. Mengkonfirmasi bahwa seseorang yang hendak memasuki sistem tersebut adalah 
orang yang tepat merupakan suatu langkah autentikasi. Proses autentikasi pada sistem komputer terjadi pada saat login. Metode untuk memastikan bahwa dokumen yang diterima memang benar dan tidak berubah adalah dengan autentikasi. Cara untuk memastikan bahwa benar dari orang yg bersangkutan adalah dengan cara mengirimkan suatu kode melalui email dan email tersebut akan dibalas oleh pemiliknya atau mengetikkan kembali kode yang dikirim. Metode dari autentikasi dapat digolongkan menjadi empat jenis yaitu: Something you know, Something you have, Something you are, dan Something you do.

\section{B. Kriptografi}

Kriptografi merupakan sebuah fungsi plaintext dan kunci kriptografi dapat dirumuskan sebagai berikut:

$$
C=F(P, k)
$$

Keterangan:

$\mathrm{P}=$ Plaintext

$\mathrm{C}=$ Ciphertext

$\mathrm{K}=$ Cryptographic Key

Konsep kriptografi seperti pada Gambar 1

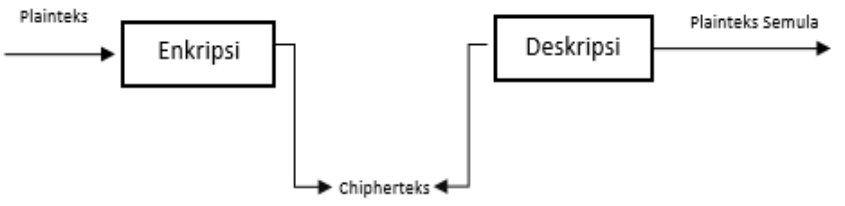

Gambar 1. Gambaran Umum Konsep Kriptografi [7]

Secara umum kriptografi dibagi menjadi dua jenis, yaitu :

\section{Kunci Simetris}

Kunci simetris adalah kriptografi yang menggunakan satu kunci yang sama untuk proses enkripsi dan proses dekripsinya. Contoh algoritma kriptografi simetris seperti DES, AES, RC4, RC6, 3DES. Gambaran umum konsep kriptografi simetris ditunjukkan pada Gambar 2

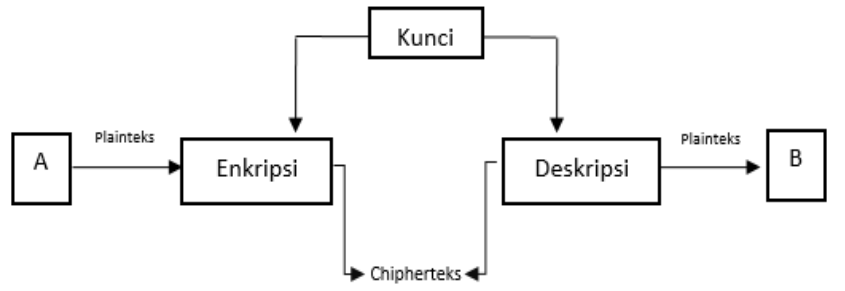

Gambar 2. Gambaran Umum Kriptografi Simetris [7]

\section{Kunci Asimetris}

Pada kriptografi kunci asimetris menggunakan kunci yang berbeda untuk proses enkripsi dan proses dekripsinya. Dalam proses enkripsi dan dapat diketahui oleh seluruh pengguna adalah kunci publik. Sedangkan untuk kunci rahasia digunakan dalam proses dekripsi dan disimpan atau dijaga keamanannya. Contoh dari algoritma kriptografi asimetris yaitu RSA, DSA, Diffie-Hellman, ElGamal, PKCS. Gambaran umum konsep kriptografi simetris ditunjukkan pada Gambar 3

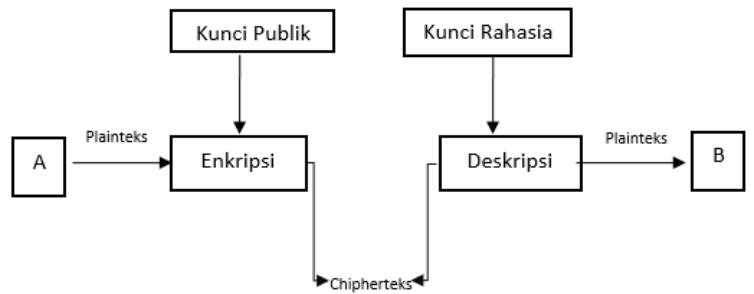

Gambar 3 Gambaran Umum Kriptografi Asimetris [7]

\section{Algoritma ElGamal}

Algoritma kriptografi ElGamal adalah contoh algoritma dengan kunci asimetris yang didasarkan pada logaritma diskrit. Taher ElGamal yang berasal dari Mesir pada tahun 1984 pertama kali mengembangkan algoritma ELGamal. Penghitungan logaritma diskrit pada bilangan modulo prima yang besar menyebabkan sangat sukar menyelesaikan Algoritma ElGamal. Algoritma ElGamal melakukan proses enkripsi pada blok-blok plainteks dan akan menghasilkan blok-blok cipherteks kemudian dilakukan proses dekripsi, yang nanti hasil tersebut akan digabungkan kembali menjadi identitas yang sama seperti plainteks [4].

ElGamal memiliki kelemahan yaitu prosesnya lebih lama dan memerlukan kapasitas pengiriman lebih besar hal itu dikarenakan cipherteks identitas yang dihasilkan mempunyai panjang dua kali lipat dari plainteks identitasnya [1]. Pada plainteks ElGamal yang sama, jika di enkripsi memberikan cipherteks yang berbeda. Hal ini dikarenakan pada saat dilakukannya proses enkripsi ada variabel yang ditentukan secara acak. Proses pembentukan kunci, enkripsi dan dekripsi merupakan proses dari algoritma ElGamal. Pada proses algoritma ElGamal terdapat beberapa parameter yang digunakan, yaitu:

- Bilangan prima $\mathrm{p}$ merupakan bilangan yang sifatnya tidak rahasia

- g merupakan bilangan acak yang bersifat rahasia

- Bilangan acak x merupakan bilangan yang sifatnya tidak rahasia

- Bilangan y merupakan bilangan yang bersifat tidak rahasia

- m merupakan Plaintext

- a dan b merupakan ciphertext

Sepasang kunci dibangkitkan pada proses pembentukan kunci dan diambil dari bilangan prima $\mathrm{p}$ yang bersifat tidak rahasia serta bilangan acak $\mathrm{g}$ dan bilangan acak $\mathrm{x}$ dengan syarat $\mathrm{x}<\mathrm{p}$ dan

$\mathrm{g}<p$, maka

$$
y=g^{x} \bmod p
$$

Kemudian pada proses enkripsi dilakukan dengan cara memilih bilangan acak k dengan syarat $1 \leq k \leq p-2$. Setiap blok plaintext dienkripsi dengan persamaan (2) dan (3)

$$
\begin{aligned}
& a=g^{h} \bmod p \\
& b=y^{x} \bmod p
\end{aligned}
$$

Selanjutnya untuk mendeskripsikan a dan b menjadi plaintext pada proses dekripsi menggunakan kunci privat $\mathrm{x}$ dan $\mathrm{p}$ dengan persamaan:

$$
(a x)^{-1}=a^{p-1-x} \bmod p
$$




$$
m=b x a^{x} \bmod p
$$

\section{A. HASIL DAN PEMBAHASANGambaran Sistem}

Gambaran dari sistem aplikasi pelaporan tindak kekekrasan dalam rumah tangga menggunakan platform android dan database firebase dilihat seperti pada gambar berikut:

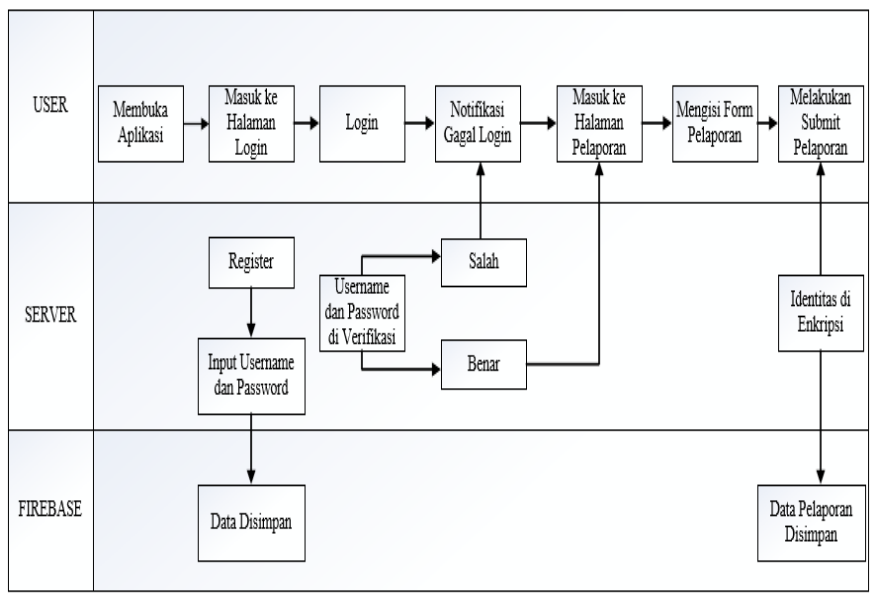

Gambar 4. Gambaran Umum Sistem

Gambar 4 merupakan gambaran umum sistem yang terdiri atas tiga bagian yakni user, server, database. Pada bagian user, dipaparkan mengenai apa saja aktivitas yang dilakukan oleh user dalam aplikasi. Pada bagian server, dipaparkan mengenai proses register user agar terdaftar dalam aplikasi serta proses otentikasi, otorisasi, dan pengamanan anonym yang menjadi sistem keamanan pada aplikasi. Pada bagian database, dipaparkan mengenai datadata apa saja yang disimpan baik itu data user maupun data pelaporan itu sendiri.

Pada sistem pelaporan tindak kekerasan dalam rumah tangga terdapat dua pengguna yang berbeda yaitu admin dan pengguna biasa. Beberapa kebutuhan fungsional pengguna seperti pada tabel I

TABEL I

KEBUTUHAN FUNGSIONAL PENGGUNA

\begin{tabular}{|c|l|l|}
\hline No. & $\begin{array}{l}\text { Kebutuhan } \\
\text { Fungsional }\end{array}$ & \multicolumn{1}{|c|}{ Keterangan } \\
\hline 1. & Email & $\begin{array}{l}\text { Pengguna memerlukan email } \\
\text { untuk beberapa proses seperti } \\
\text { otentikasi otorisas dan } \\
\text { verifikasi informasi }\end{array}$ \\
\hline 2. & Password & $\begin{array}{l}\text { Pengguna memerlukan } \\
\text { password untuk masuk ke } \\
\text { sistem melalui proses } \\
\text { otentikasi }\end{array}$ \\
\hline 3. & User UID & $\begin{array}{l}\text { Pengguna memerlukan User } \\
\text { UID untuk proses otorisasi } \\
\text { dan mengakses data pada } \\
\text { database }\end{array}$ \\
\hline
\end{tabular}

Sedangkan beberapa kebutuhan fungsional dari sistem ditunjukkan pada tabel II
TABEL II

KEBUTUHAN FUNGSIONAL SISTEM

\begin{tabular}{|c|c|c|}
\hline No. & $\begin{array}{l}\text { Kebutuhan } \\
\text { Fungsional }\end{array}$ & Keterangan \\
\hline 1. & Email & $\begin{array}{l}\text { Sistem memerlukan email } \\
\text { untuk proses otentikasi, } \\
\text { otorisasi dan verifikasi } \\
\text { informasi }\end{array}$ \\
\hline No. & $\begin{array}{l}\text { Kebutuhan } \\
\text { Fungsional }\end{array}$ & Keterangan \\
\hline 2. & Password & $\begin{array}{l}\text { Sistem memerlukan } \\
\text { password untuk masuk ke } \\
\text { sistem melalui proses } \\
\text { otentikasi }\end{array}$ \\
\hline 3. & $\begin{array}{l}\text { Nomor } \\
\text { Telepon }\end{array}$ & $\begin{array}{l}\text { Sistem memerlukan } \\
\text { nomor telepon untuk } \\
\text { masuk ke dalam sistem } \\
\text { melaluiproses otentikasi }\end{array}$ \\
\hline 4. & User UID & $\begin{array}{l}\text { Pengguna memerlukan } \\
\text { User UID untuk proses } \\
\text { otorisasi dan mengakses } \\
\text { data pada database }\end{array}$ \\
\hline 5. & Rules & $\begin{array}{l}\text { Sistem memerlukan } \\
\text { sebuah rules untuk } \\
\text { mendefinisikan hak akses } \\
\text { pengguna } \\
\text { mengakses database }\end{array}$ \\
\hline 6. & $\begin{array}{c}\text { Data } \\
\text { Laporan } \\
\text { Kekerasan }\end{array}$ & $\begin{array}{l}\text { Sistem memerlukan data } \\
\text { laporan kekerasan untuk } \\
\text { disimpan pada database }\end{array}$ \\
\hline
\end{tabular}

B. Tampilan Aplikasi

Berikut merupakan tampilan aplikasi tindak kekerasan dalam rumah tangga

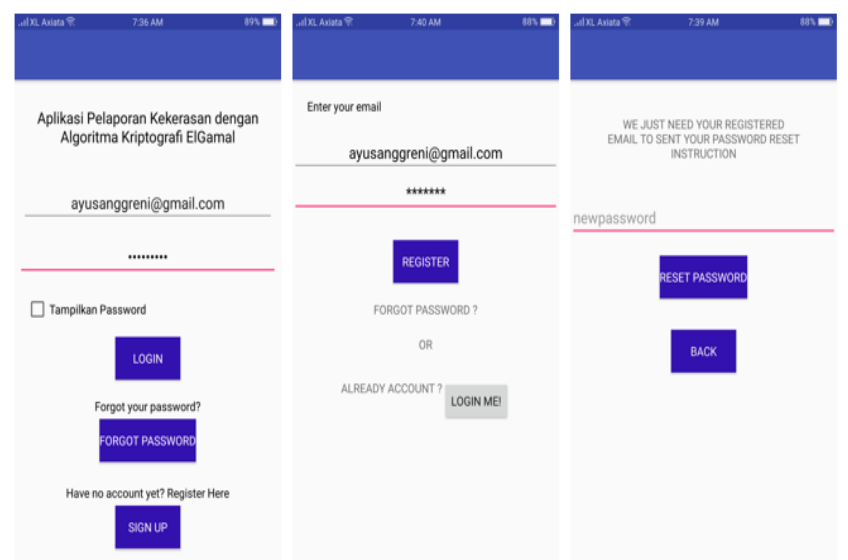

Gambar 5. Tampilan halaman Login, Register dan Forgot password

\section{Avalanche Effect}

Hasil enkripsi dengan menggunakan algoritma kriptografi ElGamal pada aplikasi pelaporan tindak kekerasan dalam rumah tangga ditunjukkan seperti pada gambar 6.

Ni Komang Ayu Sri Anggreni: Sistem Pengamanan Anonym dengan... 
INEO PELAPORAN KEKERASAN

973408421408136226720315782816995472546 973408421408136226720315782816995472546 2142777296

2434287121435308676201486151915513131728 8297922882107164219701001269720882106 258414312491144927462177154412842631837
3468551464198644262453413248850927982114 14565061961224514092587126654713091079 2992671016240326814662712786192517262161 112021662104

7052437287417562713182412072651373407443 1846199746893625751191651956394891568 146514118315151901182015428685411867590 18732269255159311772142277845026862258 228925703612195500549138011724775792872 2823154140918438072300956958 842896215679120281352148927352127707277 14382976491024216823931484

Coba Aplikasi Pelaporan Kekerasan dengan Algoritma ElGamal

\section{DONE}

Gambar 6. Tampilan hasil enkripsi pada aplikasi

Algoritma enkripsi ElGamal memiliki masukan Plain. Text yang akan dikonversikan ke dalam nilai angka desimal dengan menggunakan tabel ASCII sehingga menghasilkan Cipher Text berupa angka desimal [6] Chiper Text kemudian disimpan dalam Database yang selanjutnya akan di konversi menjadi bentuk biner dengan menggunakan konverter biner secara online. Setelah dilakukannya konversi terhadap Chiper Text maka dapat diketahui jumlah bit yang berbeda dari Plain Text yang telah mengalami sedikit perubahan. Hai ini bertujuan untuk menghitung avalanche effect.

Pengujian Avalanche Effect dilakukan dengan menggunakan 10 sampel Plain Text yang berbeda. Berdasarkan hasil konversi diketahui perbedaan jumlah bit Cipher Text seperti pada Tabel III berikut

TABEL III

PENGUJIAN AVALANCHE EFFECT

\begin{tabular}{|c|c|c|}
\hline No. & Plain Text & $\begin{array}{c}\text { Jumlah Bit } \\
\text { Berbeda }\end{array}$ \\
\hline \multirow{2}{*}{1.} & Anggreni & \multirow{2}{*}{368} \\
\hline & Anggremi & \\
\hline \multirow{2}{*}{2.} & Cok Ratih & \multirow{2}{*}{344} \\
\hline & Cok Satih & \\
\hline \multirow{2}{*}{3.} & Indira & \multirow{2}{*}{248} \\
\hline & Indisa & \\
\hline \multirow{2}{*}{4.} & Denpasar & \multirow{2}{*}{344} \\
\hline & Denpadar & \\
\hline \multirow{2}{*}{5.} & Pegawai & \multirow{2}{*}{336} \\
\hline & Pegarai & \\
\hline \multirow{2}{*}{6.} & Mahasiswa & \multirow{2}{*}{408} \\
\hline & Mahasiswi & \\
\hline \multirow{2}{*}{7.} & Renon & \multirow{2}{*}{200} \\
\hline & Renom & \\
\hline \multirow{2}{*}{8.} & Panjer & \multirow{2}{*}{248} \\
\hline & Panjar & \\
\hline \multirow{2}{*}{9.} & Suariani & \multirow{2}{*}{352} \\
\hline & Suariami & \\
\hline No. & Plain Text & $\begin{array}{c}\text { Jumlah Bit } \\
\text { Berbeda }\end{array}$ \\
\hline \multirow{2}{*}{10.} & Perumahan & \multirow{2}{*}{376} \\
\hline & Perumaham & \\
\hline
\end{tabular}

Perhitungan avalanche effect dapat dilakukan dengan melihat jumlah bit berbeda seperti yang ditunjukkan pada Tabel III. Sehingga nilai hasil perhitungan avalanche effect seperti pada tabel IV

TABEL IV

HASIL PERHITUNGAN AVALANCHE EFFECT

\begin{tabular}{|c|c|c|}
\hline No. & Plain Text & Avalanche Effect \\
\hline \multirow{2}{*}{1.} & Anggreni & \multirow{2}{*}{$64,7 \%$} \\
\hline & Anggremi & \\
\hline \multirow{2}{*}{2.} & Cok Ratih & \multirow{2}{*}{$52,4 \%$} \\
\hline & Cok Satih & \\
\hline \multirow{2}{*}{3.} & Indira & \multirow{2}{*}{$56,3 \%$} \\
\hline & Indisa & \\
\hline \multirow{2}{*}{4.} & Denpasar & \multirow{2}{*}{$58,9 \%$} \\
\hline & Denpadar & \\
\hline \multirow{2}{*}{5.} & Pegawai & \multirow{2}{*}{$65,6 \%$} \\
\hline & Pegarai & \\
\hline \multirow{2}{*}{6.} & Mahasiswa & \multirow{2}{*}{$61,8 \%$} \\
\hline & Mahasiswi & \\
\hline \multirow{2}{*}{7.} & Renon & \multirow{2}{*}{$53,1 \%$} \\
\hline & Renom & \\
\hline \multirow{2}{*}{8.} & Panjer & \multirow{2}{*}{$56,3 \%$} \\
\hline & Panjar & \\
\hline \multirow{2}{*}{9.} & Suariani & \multirow{2}{*}{$57,1 \%$} \\
\hline & Suariami & \\
\hline \multirow{2}{*}{10.} & Perumahan & \multirow[t]{2}{*}{$56,6 \%$} \\
\hline & Perumaham & \\
\hline
\end{tabular}

Berdasarkan hasil perhitungan Avalanche Effect dari 10 sampel yang digunakan dapat dilihat seperti grafik pada gambar 7

\section{Avalanche Effect}

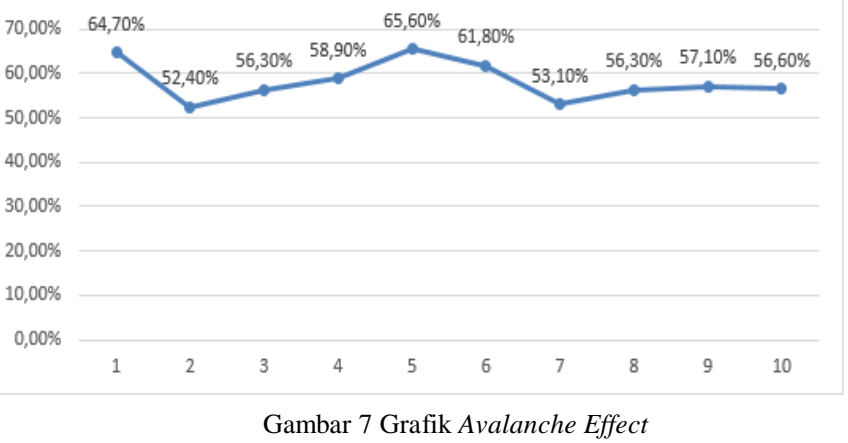

Grafik pada gambar 7 menunjukkan hasil perhitungan Avalanche Effect berkisar antara 50-60\%. Dengan menggunakan 10 sampel cipher text rata-rata Avalanche Effect keseluruhan adalah 58,2\%. Hal ini menunjukkan bahwa proses pengamanan yang dilakukan telah dikategorikan baik karena telah memenuhi syarat dari Avalanche Effect yaitu keluaran perhitungan atas perubahan bit menghasilkan 40-60\% dari keseluruhan bit Cipher Text.

\section{KESIMPULAN}

Berdasarkan hasil penelitian dapat dilihat bahwa algoritma enkripsi ElGamal memiliki masukan Plain Text yang akan dikonversikan ke dalam nilai angka desimal dengan menggunakan tabel ASCII sehingga menghasilkan Cipher Text berupa angka desimal. 
Tingkat keamanan aplikasi pelaporan tindak kekerasan dalam rumah tangga ini dinyatakan aman dari serangan kriptanalis yang diukur dari pengujian Avalanche Effect dengan menggunakan 10 cipher text yang berbeda didapatkan hasil rata-rata avalanche effect sebesar 58,2 \% dimana hasil tersebut dikategorikan baik mengingat syarat dari Avalanche Effect yaitu keluaran perhitungan atas perubahan bit menghasilkan 40-60 \% dari keseluruhan bit Cipher Text.

\section{REFERENSI}

[1] Al-Anshori, Faqihuddin., Aribowo, Eko. 2014. Impelemtasi Algoritma Kriptografi Kunci Publik ElGamal Untuk Proses Enkripsi dan Dekripsi Guna Pengamanan File Data. Jurnal Sarjana Teknik Informatika, Vol.2 No.2

[2] Himawan, Cindy., Wibowo, Toni., Sulistyo, Budi. 2016. Studi Perbandingan Algoritma RSA dan Algoritma ElGamal. Presiden University.

[3] Sharma, Ankush., Attri, Jyoti., Devi, Aarti., Sharma, Pratibha. 2014. Implementation \& Analysis of RSA and ElGamal Algorithm. Asian J. of Adv. BasicSci : 2(3). 125-129

[4] Mulya, Megah., 2013. Perbandingan Kecepatan Algoritma Kriptografi Asimetri. Journal of Research in Computer Science and Applications, Vol.1 No.2

[5] Karima, Aisyatul., Handoko, L. Budi., Saputro, Ari. 2017. Pemfaktoran Bilangan Prima pada Algoritma ElGamal untuk Keamanan Dokumen PDF. JNTETI, Vol.6, No.3

[6] Triase. 2015. Kriptografi ElGamal Menggunakan Metode Mersenne. Jurnal Ilmiah "Integritas". Vol.1 No.4

[7] Kabetta, Herman. 2017. Analisis Kompleksitas Waktu Algoritma Kriptografi ElGamal dan Data Encryption Standard. Jurnal Teknikom. Vol.1 No.1 ISSN: 2598-294X

[8] Parmadi, B. (2017). Implementasi Algoritma Kriptografi Elgamal pada Data Text, Journal of Information and Technology, Vol.05 No 01.

[9] Vishwakarma, Manila., Jain Sourabh. (2018). An Efficient Cryptosystem to Perform Encryption and Decryption of Data.

[10] Djellalbia, Amina., Badache, Nadjib., Benmeziane, Souad., Bensimessaoud, Sihem. 2016. Anonymous Authentication Scheme in e-Health Cloud Environment. $11^{\text {th }}$ International Conference for Internet Technology and Secured Transactions (ICITST). 47-52

[11] Nivedita Bisht dan Sapna Singh.. "A Comparative Study of Some Symmetric and Asymmetric Key Cryptography Algorithms". International Journal of Innovative Research in Science Engineering and Technology Vol. 4 Issue 3. 2015. 
\{ halaman ini sengaja di kosongkan \} 